\title{
7. Bibliographische Hinweise zur Epoche der Jahrhundertwende
}

Bauer, Roger (Hg.) (1977): Fin de siècle. Zur Literatur und Kunst der Jahrhundertwende. Frankfurt.

Fischer, Jens Malte (1978): Fin de siècle. Kommentar einer Epoche. München.

Greve, Ludwig und Werner Volke (Hg.) (1974): Jugend in Wien. Literatur um 1900. Sonderausstellung des Schiller-Nationalmuseums, Marbach. Katalog Nr. 24. München.

Hermand, Jost (1972): Der Schein des schönen Lebens. Studien zur Jahrhundertwende. Frankfurt.

Johnston, William M. (1972): Österreichische Kultur- und Geistesgeschichte. Gesellschaft und Ideen im Donauraum 1848-1938. Wien. Amerikanische Originalfassung Berkeley 1972.

Morton, Frederic (1979): Schicksalsjahr 1888/89. Wien. Amerikanische Originalfassung Boston 1979.

Rasch, Wolfdietrich (1986): Die literarische Décadence um 1900. München.

Ruprecht, Erich u. a. (Hg.) (1970): Literarische Manifeste der Jahrhundertwende. 1890-1910. Stuttgart.

Schorske, Carl (1982): Wien. Geist und Gesellschaft im fin de siècle. Amerikanische Originalfassung 1980.

Szondi, Peter (1959): Theorie des modernen Dramas (1880-1950). Frankfurt.

Waissenberger, Robert (Hg.) (1985): Traum und Wirklichkeit. Wien 1870-1930. Wien.

Wunberg, Gotthart (Hg.) (1971): Die literarische Moderne. Dokumente zum Selbstverständnis der Literatur der Jahrhundertwende.

Ders. (Hg.) (1976): Das Junge Wien. Österreichische Literatur- und Kunstkritik 1867-1902. 2 Bde. Tübingen.

Ders. (Hg.) (1981): Die Wiener Moderne. Literatur, Kunst und Musik zwischen 1890 und 1910. Stuttgart.

Worbs, Michael (1983): Nervenkunst. Literatur und Psychoanalyse im Wien der Jahrhundertwende. Frankfurt.

Žmegač, Viktor (Hg.) (1981): Deutsche Literatur der Jahrhundertwende. Königstein. 